$\begin{array}{ll}\text { Received } & : 15 \text { Maret } 2020 \\ \text { Revised } & : 2 \text { April } 2020 \\ \text { Accepted } & : 25 \text { April } 2020 \\ \text { Online } & : 28 \text { April } 2020 \\ \text { Published } & : 30 \text { April } 2020\end{array}$

\title{
Analisa Komparasi Perangkat Speech Recognizing dan Potensinya dalam Membantu Proses Pembelajaan Difabel Rungu Guna Terciptanya Kampus Inklusif Di Era 4.0
}

\author{
Chandra Halim.M ${ }^{1, a)}$, Febri Satria ${ }^{1, b)}$ \\ ${ }^{1)}$ Departemen Fisika, Fakultas Matematika dan Ilmu Pengetahuan Alam, Universitas Gadjah Mada

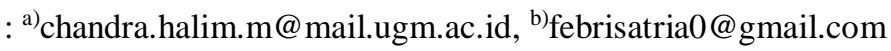

\begin{abstract}
The lack of facilities and infrastructures for students with special needs will hamper the learning process. In fact, this has been explained in the definition of inclusive education which is to accommodate students with special needs to comprehend the material in the class. The fact is that there are only public facilities such as the guiding block for the blind, and some interpreters in the class to explain the material. This situation is exacerbated by the limitations of an interpreter to explain scientific terms. Therefore, we need a technology that can help deaf people to comprehend the material in the classroom directly. The technology is speech recognizing device. This device enables to process input signals in the form of sound and is converted into text. This technology enables deaf people to comprehend material in the classroom without an interpreter. The research method is inferential statistics and observations. Observations were made by measuring 26 respondents speaking speed to obtain data using 3 different applications namely Speech Notes, Voice Notebooks, Speech to Text. Afterthat, the words obtained in the application are compared with the actual text to see the accuracy of each application. By using inferential statistics, the correlation test values obtained in the application of Voice Notebooks, Speech Notes, Speech to Text are 0.386,0.351, and 0.152, respectively. By using 5\% significance level, we found that the most accurate speech recognizing application is Voice Notebook. Due to Voice Notebook application, we can support the special students in learning process in the class.
\end{abstract}

Keywords: Inferential Statistics, Speaking Speed, Speech Recognizing

\begin{abstract}
ABSTRAK
Minimnya sarana dan prasana bagi peserta didik yang berkebutuhan khusus akan menghambat proses pembelajaran. Padahal, hal ini sudah dijelaskan pada definisi pendidikan inklusi yakni mengakomodasi peserta didik yang berkebutuhan khusus untuk memahami materi di dalam kelas. Faktanya ialah hanya tersedia fasilitas umum seperti guiding block untuk difabel netra, dan beberapa orang interpreter yang ada di dalam kelas untuk menjelaskan materi seminar. Keadaan ini diperburuk dengan keterbatasan seorang interpreter untuk menjelaskan istilah ilmiah yang ada. Oleh karena itu, diperlukan suatu teknologi yang dapat membantu para disabilitas rungu dalam memahami materi di dalam kelas secara langsung. Teknologi yang akan digunakan adalah
\end{abstract}


perangkat speech recognizing. Perangkat ini memungkinkan untuk memproses sinyal masukan berupa suara dan diubah dalam bentuk teks. Teknologi ini memungkinkan seorang disabilitas rungu untuk memahami materi pelajaran di dalam kelas tanpa interpreter. Metode penelitian yang dilakukan adalah statistika inferensial dan observasi. Observasi dilakukan dengan cara mengukur kecepatan berbicara 26 responden untuk diperoleh data dengan menggunakan 3 aplikasi yang berbeda yaitu Speech Notes, Voice Notebook, Speech to Text. Setelah itu, kata yang diperoleh pada aplikasi dibandingkan dengan teks yang sebenarnya untuk melihat akurasi setiap aplikasi. Dengan menggunakan statistik inferensial diperoleh nilai uji korelasi pada aplikasi Speech Notes, Voice Notebook, Speech to Text berturut-turut sebesar 0,386, 0,351 dan 0,152. Dengan menggunakan syarat taraf signifikansi 5\%, diperoleh bahwa aplikasi speech recognizing yang paling akurat adalah Voice Notebook. Dengan adanya aplikasi Voice Notebook, diharapkan akan adanya suatu sistem yang dibangun untuk membantu mahasiswa dalam memahami materi di kelas.

Kata-kata kunci: Statistik Inferensial, Kecepatan Membaca, Speech Recognizing.

\section{PENDAHULUAN}

Derasnya arus globalisasi seakan-akan menyulap masyarakat untuk mendorong dan mengembangkan diri untuk menjadi lebih baik. Di tengah-tengah zaman yang semakin canggih atau sering disebut dengan revolusi industri 4.0, dunia menuntut masyarakat agar dapat meminimalisir kerja untuk mendapatkan hasil yang maksimal. Oleh karena itu, peran pendidikan untuk mewujudkan hal tersebut sangat diperlukan. Berdasarkan definisi, pendidikan adalah usaha sadar dan terencana yang dilakukan oleh seseorang untuk mewujudkan suasana belajar agar kedepannya dapat mengembangkan potensi diri seperti potensi spiritual, keterampilan dll. Secara garis besar, pendidikan meliputi pendidikan formal dan informal. Menurut Sudarwan (2010), pendidikan formal merupakan pendidikan yang diselenggarakan oleh sekolah-sekolah pada umumnya sedangkan pendidikan informal merupakan kegiatan yang diselenggarakan di luar pendidikan formal seperti pengajian, TPA dll. Peran pendidikan formal maupun informal sangatlah berpengaruh pada proses kehidupan seseorang. Berdasarkan definisi diatas, diperoleh kesimpulan bahwa tujuan pendidikan adalah membentuk seseorang agar menjadi manusia paripurna yang mandiri dan dapat bertanggung jawab atas lingkungannya sehingga dapat mewujudkan revolusi industri 4.0.

Pada seseorang yang memiliki keterbatasan fisik, terdapat jenis pendidikan khusus yaitu pendidikan inklusif. Pendidikan inklusif adalah sistem penyelenggaraan pendidikan yang memberikan kesempatan kepada semua peserta didik yang memiliki kelainan dan memiliki potensi kecerdasan dan atau bakat istimewa untuk mengikuti pendidikan atau pembelajaran dalam satu lingkungan pendidikan secara bersama-sama dengan peserta didik pada umumnya (Kauchak dan Eggen 2012). Pendidikan inklusif memungkinkan Anak Berkebutuhan Khusus (ABK) untuk ikut serta belajar bersama dengan anak normal lainnya yang sebaya di kelas yang terdekat dengan tempat tinggalnya. Jenjang pendidikan inklusif meliputi pendidikan dasar, menengah, atas bahkan perguruan tinggi. Berdasarkan data yang dihimpun oleh Pusat Studi dan Layananan Disabilitas Universitas Brawijaya (PSLD UB) jumlah mahasiswa disabilitas yang belajar di UB dari tahun 2015 sampai tahun 2019 terdapat sebanyak 157 mahaiswa dengan persentase difabel tulis sebanyak 49\%. Dengan jumlah mahasiswa sebanyak itu, diperlukan usaha yang lebih besar dari pihak pemerintah, universitas bahkan mahasiswa itu sendiri dalam penyelenggaraan pendidikan inklusif di pendidikan tinggi.

Ironisnya, pelaksanaan pendidikan inklusi di Indonesia sendiri belum sepenuhnya dapat dikatakan baik. Hal ini dapat dibuktikan dengan minimnya fasilitas yang membantu para kaum disabilitas serta abainya para pengajar perguruan tinggi dalam menanggapi 
permasalahan tersebut. Fasilitas yang disediakan oleh pihak universitas seperti jalur pemandu (guiding block), kursi roda dll dinilai masih kurang efektif. Pasalnya, fasilitas yang diberikan hanya mendukung dalam aspek aksesibilitas bukan pada proses belajar mengajar, khususnya difabel rungu (Hanjarwati dan Aminah 2014). Dewasa ini, belum disediakannya fasilitas yang memadai untuk difabel rungu. Faktanya, para difabel rungu hanya dapat belajar melalui penjelasan berupa tulisan yang ditulis oleh teman sebangku. Keadaan ini tentunya sangat tidak efektif jika dipandang dari dua belah pihak. Oleh karena itu, diperlukannya suatu inovasi yang dapat menanggulangi permasalahan difabel rungu dalam proses kegiatan belajar mengajar.

Terdapat banyak jenis disabilitas seperti disabilitas fisik, mental, ganda dll. Tetapi dalam tulisan ini, disabilitas yang dibicarakan terbatas pada disabilitas fisik yang berfokus pada difabel rungu. Disabilitas fisik berarti mereka yang memiliki keterbatasan fisik dalam jangka waktu lama (Utari, 2014). Pada disabilitas fisik khususnya difabel rungu, sudah pasti mengalami kesulitan dalam memahami pelajaran yang diberikan. Difabel tuna rungu kurang memiliki pemahaman infomasi verbal. Hal ini menyebabkan orang tersebut sulit menerima materi yang bersifat abstrak, sehingga dibutuhkan media untuk memudahkan pemahaman suatu konsep pada penyandang tuna rungu. Kemampuan penguasaan kosakata pada temanteman yang mengalami gangguan pendengaran jelas berbeda karena keterbatasan fungsi pendengaran sehingga teman-teman tuna rungu cenderung memiliki hambatan belajar atau berkomunikasi dengan orang lain disekitarnya (Baihaqi dkk 2008).

Kemampuan penguasaan kosakata penyandang tuna rungu dapat dilihat dari kemampuan memahami teks bacaan dan/atau memahami mimik wajah lawan bicara ketika menyampaikan kata yang diucapkan. Penelitian ini berfokuskan pada tujuan membantu para mahasiswa difabel tunarungu dalam memahami materi yang disampaikan di depan kelas dengan cara pendekatan pemahaman materi/kosakata dalam bentuk teks. Nurgiyantoro, (2014) menyatakan bahwa penguasaan kosakata adalah kemampuan untuk mempergunakan kata-kata. Kemampuan untuk memahami diwujudkan dalam kegiatan membaca dan menyimak, sedangkan kemampuan mengekspresikan diwujudkan dalam kegiatan menulis dan berbicara. Penguasaan kosakata merupakan hal yang sangat penting dalam mencapai penguasaan bahasa, semakin banyak kosakata yang dimiliki seseorang maka semakin banyak pula ide dan gagasan yang dikuasai seseorang. Penguasaan kosakata merupakan ukuran pemahaman seseorang terhadap kosakata suatu bahasa dan kemampuannya menggunakan kosakata tersebut baik secara lisan maupun tertulis.

Pada penelitian ini, akan diteliti tentang aplikasi speech recognizing terbaik yang nantinya akan digunakan pada suatu sistem yang dapat direalisasikan pada difabel rungu. Dengan demikian, difabel rungu dapat mengikuti proses belajar mengajar dengan baik layaknya mahasiswa lainnya.

\section{METODE PENELITIAN}

\section{Persiapan Bahan}

Persiapan bahan dimulai dengan mempersiapkan teks bacaan sebanyak 50 kata. Teks yang digunakan berisi tentang penerapan ilmu fisika dalam kehidupan sehari-hari. Setelah itu, persiapan dilanjutkan dengan memasang aplikasi speech recognizing pada smartphone yang sudah terintegrasi dengan earphone untuk digunakan sebagai instrumen pengambil data. 


\section{Pengujian}

Adapun langkah pengujian bahan dalam penelitian ini adalah sebagai berikut.

1. Teks sebanyak 50 kata dibaca oleh responden dan diulang sebanyak 2 kali untuk masingmasing aplikasi.

2. Waktu yang dibutuhkan untuk membaca teks tiap kali dihitung untuk memperoleh nilai kecepatan membaca.

3. Jumlah kata salah yang terdeteksi dengan menggunakan aplikasi speech recognizing dihitung untuk menentukan kesalahan aplikasi.

4. Diperoleh nilai data kecepatan membaca dan jumlah kata yang salah dalam setiap percobaan dan setiap aplikasi.

5. Data tersebut diuji dengan uji validitas, korelasi serta realibilitas.

\section{Metode Analisa Data}

Menghitung Kecepatan Membaca dilakukan dengan menggunakan Persamaan 1.

$$
v(\mathrm{kpm})=\frac{\text { jumlah } \mathrm{kata}}{\text { menit }}=\frac{50}{\text { menit }}
$$

Menghitung Persentase Kesalahan Kata dilakukan dengan menggunakan Persamaan 2.

$$
P K=\frac{\text { jumlah kata salah atau tidak terdeteksi }}{50} \times 100 \%
$$

Uji Korelasi, Validitas dan Realibilitas dilakukan dengan menggunakan Persamaan 3.

$$
r_{x y}=\frac{N \sum X Y-\sum X \sum Y}{\sqrt{\left(N \sum X^{2}-\left(\sum X\right)^{2}\right)\left(N \sum Y^{2}-\left(\sum Y\right)^{2}\right)}}
$$

Dengan mengetahui nilai $r_{x y}$ yaitu koefisien korelasi antara variabel $\mathrm{X}$ dan variabel $\mathrm{Y}$ maka akan diperoleh kesimpulan suatu data dapat berhubungan satu sama lain (korelasi) atau tidak, serta dapat mengetahui apakah suatu instrumen yang diperoleh valid atau tidak. Selain itu, dengan menggunakan nilai koefisien relasi pula, akan diperoleh kesimpulan bahwa suatu instrumen disebut realibel atau tidak. Dengan menggunakan ketentuan yaitu jika nilai koefisien relasi $\left(r_{x y}\right)$ yang diperoleh lebih besar atau sama dengan nilai $r_{x y}$ dalam tabel taraf signifikansi $5 \%$ atau $1 \%$ maka data tersebut dapat dikatakan realibel dan valid. Realibel berarti suatu instrumen dapat dipergunakan untuk mengumpulkan data dan dapat dipertanggungjawabkan. Valid berarti suatu instrumen dapat mengukur suatu data yang ingin diukur (Nurdiyantoro dkk 2012).

\section{HASIL DAN PEMBAHASAN}

Penelitian ini bertujuan untuk menentukan aplikasi speech recognizing yang paling sensitif dalam menganalisa suara untuk diubah menjadi bentuk teks sehingga dapat digunakan difabel rungu dalam membantu proses kegiatan belajar mengajar. Dalam menentukan aplikasi yang terbaik dalam mengenali suara tersebut, dilakukan pengukuran 
kecepatan membaca dengan menggunakan teks yang telah disediakan sebanyak 50 kata kepada 26 responden. Kecepatan membaca dilakukan untuk mengetahui kemampuan aplikasi dalam memahami dan mengintepretasi suara yang kemudian dikonversi menjadi teks yang dapat dibaca oleh semua orang. Terdapat 3 buah aplikasi yang digunakan yaitu Voice Notebook, Speech Notes, dan Speech to Text yang diunduh dari playstore smartphone Android. Pengukuran dilakukan sebanyak dua kali untuk setiap aplikasi oleh masing-masing responden. Pengukuran ini dilakukan dengan tujuan untuk mengetahui rerata nilai besaran yang diukur dan hubungan korelasi dari data yang diperoleh pada hasil pengukuran. Proses pengambilan data diambil dengan cara meminta responden untuk membaca teks sebanyak 50 kata kemudian diukur waktu yang dibutuhkan untuk menyelesaikan seluruh teks tersebut.

Setelah data waktu diperoleh, kemudian dapat diketahui nilai kecepatan membaca yang masing-masing responden. Data kecepatan membaca yang terekam oleh tiap aplikasi ditunjukkan pada Gambar 1 hasil pengukuran. Selain diperoleh data kecepatan membaca masing-masing responden untuk setiap aplikasi, diperoleh pula hubungan persentase kebenaran dan kecepatan membaca ditunjukkan pada Gambar 2. Oleh karena itu, dengan menggunakan data kecepatan membaca dan grafik hubungan persentase kebenaran dan kecepatan membaca diharapkan dapat memperoleh aplikasi speech recognizing yang terbaik.

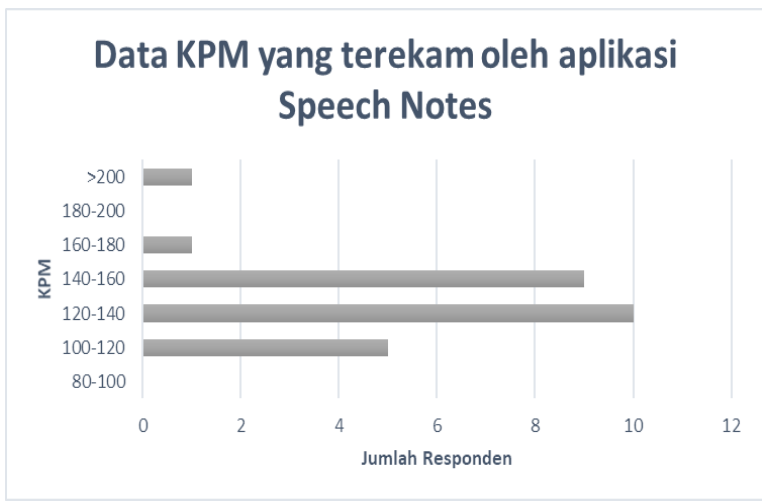

(a)

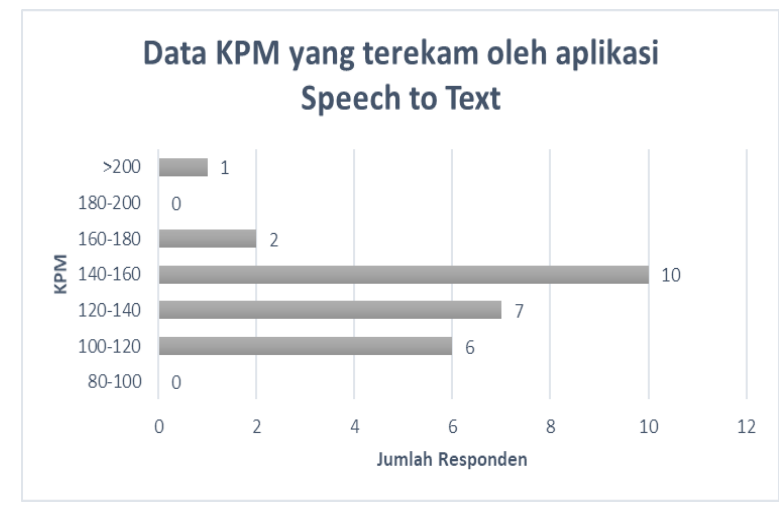

(b)

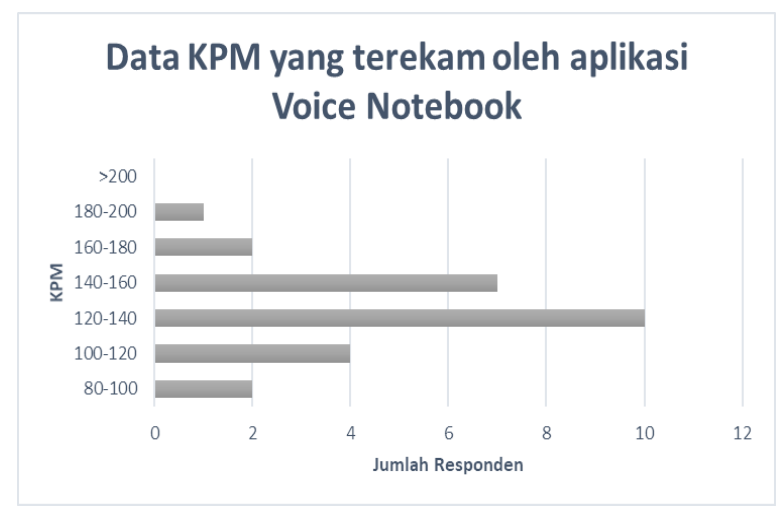

(c)

GAMBAR 1. Hasil populasi perhitungan kata per menit (kpm) dari masing-masing aplikasi (a) Speech Notes, (b) Speech To Text, dan (c) Voice Notebook. 


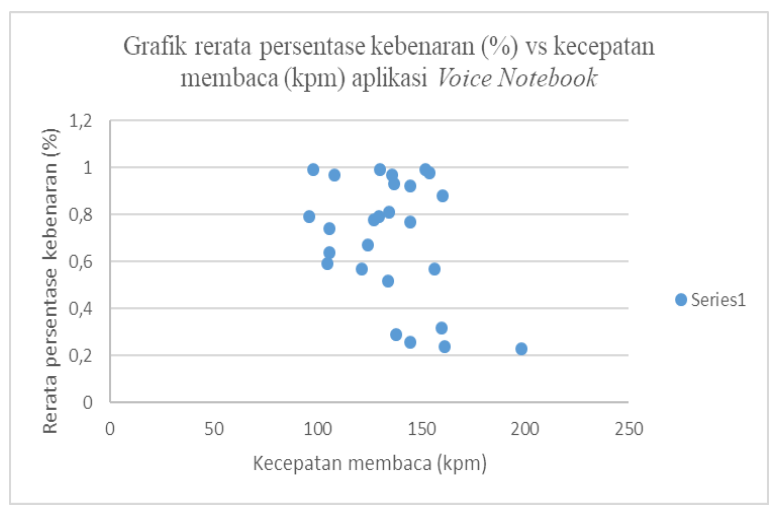

(a)

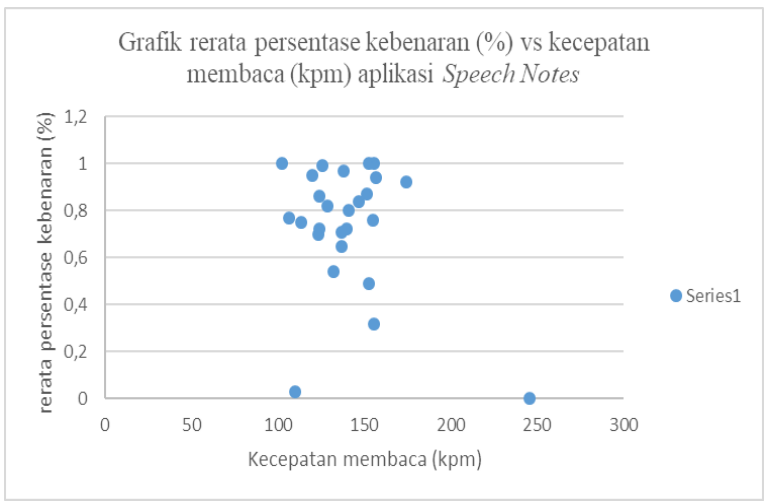

(b)

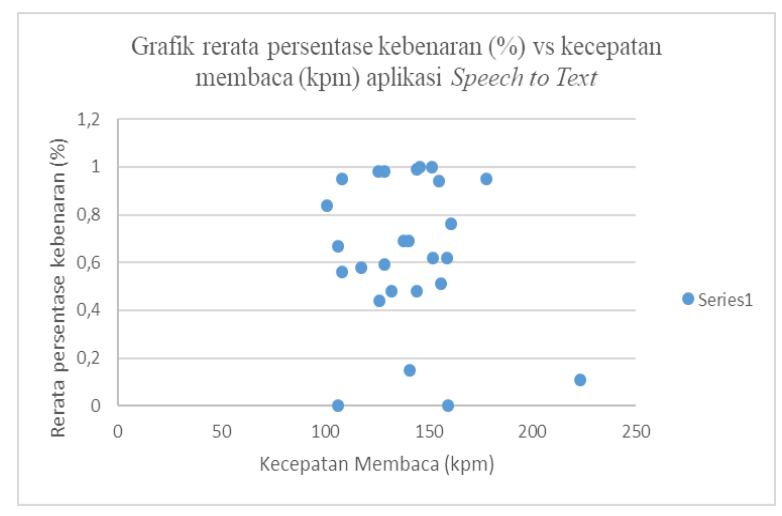

(c)

GAMBAR 2. Grafik hubungan antara rerata persentasi kebenaran (\%) dengan kecepatan membaca (kpm) untuk aplikasi (a) Voice Notebook, (b) Speech Notes dan (c) Speech to Text secara berurutan

Setelah mendapatkan data kecepatan membaca dan jumlah kata yang benar, digunakan analisis statistik untuk membandingkan satu aplikasi dengan aplikasi lainnya. Analisis yang digunakan yaitu analisis korelasi, validitas dan realibilitas. Analisis ini memerlukan nilai $r_{x y}$ yang merupakan nilai korelasi variabel $\mathrm{X}$ dan $\mathrm{Y}$ yang diperoleh dengan menggunakan persamaan (3). Apabila nilai $r_{x y}$ yang diperoleh dari data hasil percobaan lebih besar atau sama dengan nilai r pada tabel korelasi Pearson pada taraf signifikansi 5\% dan 1\%, maka data tersebut dapat dikatakan memiliki hubungan valid serta realibel. Realibel berarti suatu instrumen dapat dipergunakan untuk mengumpulkan data dan dapat dipertanggungjawabkan. Valid berarti suatu instrumen dapat mengukur suatu data yang ingin diukur. Dengan menggunakan persamaan (3) diperoleh nilai korelasi sebagai berikut:

TABEL 1. Perbandingan nilai besaran yang diperoleh pada masing-masing aplikasi

\begin{tabular}{lccc}
\hline \multirow{2}{*}{ Aspek perbandingan } & \multicolumn{3}{c}{ Aplikasi } \\
\cline { 2 - 4 } & Voice notebook & Speech to text & Speech notes \\
\hline Uji Korelasi & -0.386 & -0.351 & -0.152 \\
Rerata Kecepatan & $134.88 \mathrm{kpm}$ & $139.82 \mathrm{kpm}$ & $140.34 \mathrm{kpm}$ \\
Rerata Persentase Kebenaran & $0.75 \%$ & $0.735 \%$ & $0.638 \%$ \\
Taraf Signifikasi yang Dipenuhi & $5 \%$ & $10 \%$ & $25 \%$ \\
\hline
\end{tabular}


Berdasarkan tabel perbandingan diatas, dapat disimpulkan bahwa untuk setiap aplikasi yang digunakan, kecepatan membaca akan berbanding terbalik dengan sensitifitas aplikasi untuk menginterpretasikan suara ke dalam bentuk tulisan. Pada bagian data serta lampiran dapat dilihat bahwa dibutuhkan waktu 18-23 detik dalam membaca teks sejumlah 50 kata untuk memperoleh hasil maksimal (seluruh kata dapat terdeteksi). Terdapat ketidaksesuaian pernyataan tersebut pada aplikasi Voice Notebook dan Speech to Text. Ketidaksesuaian ini dapat diakibatkan oleh faktor tinggi rendahnya suara responden, kebisingan sekitar, pelafalan yang kurang jelas dsb. Oleh karena itu, diperlukan jumlah responden yang lebih banyak serta pengoptimalan aplikasi tersebut sehingga aplikasi ini dapat diterapkan pada proses kegiatan belajar mengajar untuk kaum disabilitas fisik jenis difabel rungu.

Sebagai acuan dalam penelitian bersifat statistik, taraf signifikansi yang diizinkan adalah $5 \%$ atau $1 \%$. Oleh karena itu, aplikasi yang terbaik adalah aplikasi yang data percobaannya memiliki taraf signifikansi $5 \%$ atau $1 \%$. Pada tabel diatas, nilai uji korelasi data yang diperoleh menggunakan aplikasi Voice Notebook $(\mathrm{r}=0,386)$ lebih besar dibandingkan nilai tabel korelasi taraf signifikansi 5\% pada data yang berjumlah 26 data $(r=0,3739)$. Pada grafik yang dihasilkan, dapat diamati bahwa data terdistribusi baik dengan nilai gradien negatif. Dengan demikian, dapat dikatakan bahwa dengan menggunakan aplikasi Voice Notebook akan diperoleh data yang berkorelasi negatif dan signifikan serta realibel dan valid.

Pada nilai uji korelasi aplikasi Speech to Text, diperoleh nilai $\mathrm{r}=0,351$ yang menyebabkan data yang diperoleh melalui aplikasi ini tidak valid dan realibel. Hal ini dikarenakan nilai uji korelasinya yang lebih rendah dibandingkan nilai uji korelasi pada tabel Pearson $(r=0,3739)$. Oleh karena itu, aplikasi ini berada pada taraf signifikasi $10 \%(r=$ 0,3172). Sama halnya pada aplikasi Speech Notes, nilai uji korelasi yang cukup rendah ( $\mathrm{r}=$ 0,152 ) menyebabkan aplikasi ini tidak valid dan realibel. Hal ini dikarenakan nilai uji korelasinya tidak mencapai nilai taraf signifikansi 5\%. Sebagai dampaknya, aplikasi ini berada pada taraf signifikansi $25 \%$. Grafik yang dihasilkan oleh kedua aplikasi memiliki kecendrungan kolektif (berkumpul pada satu titik). Hal ini disebabkan karena sensitifitas aplikasi yang cendrung sama untuk setiap pengambilan data pada responden sehingga menunjukan nilai korelasi yang rendah. Oleh karena itu, hasil aplikasi Speech to Text dan Speech Notes bernilai tidak valid dan realibel serta tidak cukup baik untuk diterapkan dalam sistem pembelajaran disabilitas fisik jenis difabel rungu.

\section{KESIMPULAN}

Berdasarkan hasil analisis serta pengolahan data diperoleh kesimpulan bahwa aplikasi terbaik yang dapat digunakan untuk disabilitas fisik jenis difabel rungu adalah aplikasi Voice Notebook dengan nilai uji korelasi lebih dari uji korelasi pada taraf signifikansi $5 \%$. Diperoleh hubungan kecepatan membaca dan sensitifitas aplikasi yakni negatif. Dengan demikian, jika kecepatan membaca tinggi maka nilai sensitifitas aplikasi akan berkurang. Diperlukan sekitar 18-23 detik untuk mendeteksi teks sebanyak 50 kata secara maksimal (terdeteksi secara keseluruhan).

\section{UCAPAN TERIMAKASIH}

Ucapan terima kasih penulis kepada bapak Dr. Eng Fahrudin Nugroho, S.Si., M.Sc sebagai dosen pembimbing dalam menulis paper ini yang telah memberikan saran yang konstruktif dalam penulis untuk menyempurnakan karya tulis ini. 


\section{REFERENSI}

Baihaqi, Cipta dan Sugiarmi. (2018). Memahami dan Membantu Anak ADHD. Bandung : Refika Aditama,

Danim, S. (2010). Pengantar Kependidikan. Bandung: Alfabeta.

Hanjarwati,S \& Aminah, S. (2014). Evaluasi Implementasi Kebijakan Pemerintah Kota Yogyakarta mengenai Pendidikan Inklusi. Jurnal : Inklusi 1(2).

Kauchak,D. \& Eggen, P. (2012). Strategi dan Model Pembelajaran: Mengajarkan Konten dan Keterampilan Berpikir. Jakarta: PT Indeks Bruce Joyce.

Nurdiyantoro, Burhan, Gunawan \& Marzuki. (2012). Buku Statistik Terapan untuk Penelitian Ilmu-Ilmu Sosial. Yogyakarta: Gadjah Mada University Press.

Nurgiyantoro, B. (2014). Penilaian Pembelajaran: Bahasa Berbasis Kompetensi. Yogyakarta: BPFE-YOGYAKARTA.

Kemahasiswaa. (2019). Statistik Mahasiswa. Universitas Brawijaya. http://psld.ub.ac.id/in/kemahasiswaan/statistik/, diakses pada tanggal 24 April 2020.

Utari,T.I. (2014). Persepsi Mahasiswa Penyandang Disabilitas Tentang Sistem Pendidikan Segregasi dan Pendidikan Inklusi. Jurnal Ilmiah Pendidikan. 